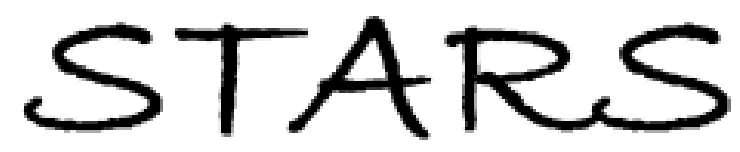

University of Central Florida

STARS

Faculty Bibliography 2000s

Faculty Bibliography

$1-1-2002$

\title{
Field detection and monitoring of explosives
}

Jehuda Yinon

University of Central Florida

Find similar works at: https://stars.library.ucf.edu/facultybib2000

University of Central Florida Libraries http://library.ucf.edu

This Article is brought to you for free and open access by the Faculty Bibliography at STARS. It has been accepted for inclusion in Faculty Bibliography 2000s by an authorized administrator of STARS. For more information, please contact STARS@ucf.edu.

\section{Recommended Citation}

Yinon, Jehuda, "Field detection and monitoring of explosives" (2002). Faculty Bibliography 2000s. 3567. https://stars.library.ucf.edu/facultybib2000/3567

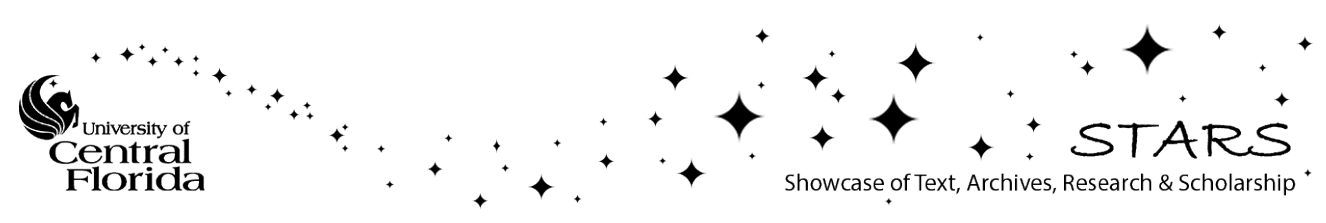




\title{
Field detection and monitoring of explosives
}

\author{
Jehuda Yinon* \\ National Center for Forensic Science, University of Central Florida, Orlando, FL 32816-2367, USA
}

\begin{abstract}
Detection of explosives in situ is of major importance in several applications: finding hidden explosives in airport luggage and in mail; screening of personnel for concealed explosives; environmental monitoring of explosives-contaminated sites; and, detection of buried landmines. Mobile and hand-held detectors have been developed for the various applications. They can be sub-divided into three classes: vapor and particle detectors; radiation detectors; and, biochemical detectors. An overview of the various explosives detectors and their principles of operation is presented. (C) 2002 Published by Elsevier Science B.V. All rights reserved.
\end{abstract}

Keywords: Hidden explosives; Environmental monitoring; Landmines

\section{Introduction}

Field detection of explosives is an extremely relevant analytical issue in law enforcement and environmental applications.

With the increasing use of explosives by terrorist groups and individuals, law enforcement and security agents are faced with the problem of detecting hidden explosives in luggage, mail, vehicles, aircraft, on travelers, and so on.

In bombing-scene investigations, it is important to find debris that includes explosive residues. Mobile and hand-held explosives detectors, similar to those used for detecting hidden explosives, can be of great help in detecting such residues.

On-site environmental detection and monitoring of traces of explosives and their degradation products is necessary in areas suspected of being contaminated by toxic explosives in

*Tel.: + 1 (407) 823-6469; Fax: +1 (407) 823-3162.

E-mail: jyinon@mail.ucf.edu order to monitor the quality of groundwater and prevent poisoning of populations of humans and animals.

The detection of landmines is an acute, urgent worldwide problem that needs specific and effective field-detection methods.

The common issue in the various applications is that one has to deal with the detection and identification of very small amounts of explosives. However, specific instruments and techniques have been developed for most applications.

\section{Detection of hidden explosives in airline luggage and mail $[1,2]$}

A list of the most widely encountered high explosives is shown in Table 1. It includes the vapor pressures of the various explosives in pure form [2]. Plasticized explosives have a lower vapor pressure.

\subsection{Vapor and trace detectors}

These detectors measure traces of characteristic volatile compounds that evaporate from the explosive or are present as particles on the explosive's container surface.

Vapor samples are collected from the target area or object by drawing ambient air into the detector. Particle samples are collected by wiping a surface with a paper filter trap or with hand-held vacuum, followed by desorption into an analyzer/detector.

In addition, chemical preconcentrators have been developed in order to increase detection sensitivity. Most preconcentrators are based on drawing in a large volume of air, collecting organic compounds - that include the explosives - from the air stream onto a chemical 
Table 1

List of widely used high explosives [2]

\begin{tabular}{|c|c|c|c|}
\hline $\begin{array}{l}\text { Trade name or } \\
\text { abbreviation }\end{array}$ & Chemical name & Major ingredients & $\begin{array}{l}\text { Vapor pressure at ambient } \\
\text { temperature [torr] }\end{array}$ \\
\hline TNT & 2,4,6-Trinitrotoluene & & $5.8 \times 10^{-6}$ \\
\hline Tetryl & $2,4,6, \mathrm{~N}$-Tetranitro-N-methylaniline & & $5.7 \times 10^{-9}$ \\
\hline RDX & 1,3,5-Trinitro-1,3,5-triazacyclohexane & & $4.4 \times 10^{-9}$ \\
\hline HMX & 1,3,5,7-Tetranitro-1,3,5,7-tetrazacyclooctane & & $3 \times 10^{-9}\left(\right.$ at $\left.100^{\circ} \mathrm{C}\right)$ \\
\hline PETN & Pentaerythritol tetranitrate & & $1.4 \times 10^{-8}$ \\
\hline NG & Glycerol trinitrate (Nitroglycerin) & & $3.1 \times 10^{-4}$ \\
\hline EGDN & Ethylene glycol dinitrate & & 0.07 \\
\hline Composition C-4 & & RDX + plasticizer & \\
\hline Composition B & & RDX + TNT + wax & \\
\hline Semtex-H & & RDX + PETN + plasticizer & \\
\hline Detasheet & & PETN + plasticizer & \\
\hline
\end{tabular}

filter, followed by vaporizing these organics into the detector.

Instruments used in the field include: gas chromatograph (GC) with electron capture detector (ECD) [3]; GC with chemiluminescence detector, also known as thermal energy analyzer (TEA); ion mobility spectrometer (IMS); and, mass spectrometer (MS).

The TEA is a nitrogen-specific detector [4-6], in which the nitroexplosive analyte, eluting from the fast GC, is introduced into a pyrolyzer. Compounds containing nitro groups decompose to produce a nitrosyl radical, $\mathrm{NO}^{\bullet}$, by catalytic reduction of the liberated $\mathrm{NO}_{2}$. The $\mathrm{NO} \cdot$ passes into a reaction chamber, where it is oxidized by ozone, forming electronically excited nitrogen dioxide, $\mathrm{NO}_{2}{ }^{*}$, which decays back to its ground state with emission of chemiluminescent light in the near-infrared region. The emitted light is detected by a photomultiplier. The light intensity is proportional to the $\mathrm{NO} \cdot$ concentration and hence to the nitrocompound concentration.

A red filter is placed in front of the photomultiplier to block any light with a spectral frequency higher than the near-infrared. Analysis takes about $18 \mathrm{~s}$. Although there is no manufacturer data on sensitivities and false-alarm rates of the TEA explosives detector [7], laboratory tests showed that the sensitivity of the GC-TEA for explosives was in the low picogram range.
The IMS [8] comprises a sample-inlet system, an atmospheric pressure ion source followed by an ion-molecule reactor, ion-drift spectrometer and a detector. Analyte ions are formed in the reactor and injected, by an electric field, into the drift region, where they are separated according to their mobility. The ion-mobility spectrum consists of a plot of ion current as a function of drift time. The drift time depends on the ionic mass: heavier ions move at a slower speed and therefore have a longer drift time.

Ions are formed in an atmospheric pressure ion source, by electrons emitted from a ${ }^{63} \mathrm{Ni}$ beta source or by electrical discharge. IMS has become a widely used technique for the detection of traces of hidden explosives [9]. For the detection of explosives, air or nitrogen at atmospheric pressure is used as both carrier and drift gases. Introduction of a reagent gas will increase sensitivity and selectivity. For example, hexachloroethane $\left(\mathrm{C}_{2} \mathrm{Cl}_{6}\right)$, will produce a reagent ion, $\mathrm{Cl}^{-}$, which will undergo ion-molecule reactions with an explosive molecule to form adduct ions of the type $(\mathrm{M}+\mathrm{Cl})^{-}$. Formation of reagent ions, such as $\mathrm{NO}_{2}^{-}$and $\mathrm{NO}_{3}^{-}$has been observed in nitramine and nitrate ester explosives, respectively, resulting in adduct ions of the type $\left(\mathrm{M}+\mathrm{NO}_{2}\right)^{-}$and $\left(\mathrm{M}+\mathrm{NO}_{3}\right)^{-}[9,10]$.

The IMS explosives detector can detect and identify RDX, PETN, TNT, Semtex, tetryl, nitrates, NG and HMX. Detection limits are in the picogram range for NG, TNT, RDX and 
PETN and in the nanogram range for tetryl and HMX. Time of analysis is $6-8 \mathrm{~s}$ [10].

A battery-operated, hand-held version of the IMS explosives detector weighs $2.6 \mathrm{~kg}$ and has an analysis time of $10-15 \mathrm{~s}$. Warm up time is less than 5 min [11]. A GC-IMS configuration for identification of explosives in post-blast samples showed detection limits in the picogram range for all tested explosives [12].

In MS, identification of analytes is by ionization and mass analysis of the ionized atoms and molecules of which the analyte is composed $[1,2]$. The principle of mass analysis is that parameters of time and space of the path of a charged particle in a force field in vacuum depend on its mass-to-charge ratio $(\mathrm{m} / \mathrm{e})$.

Ionization methods that have been used in MS explosive detectors are: atmospheric pressure ionization (API) with corona discharge $[13,14]$; atmospheric glow discharge ionization (ASGDI) [15]; and, atmospheric sampling photoionization [16]. Although the mass analyzer has to be under vacuum, mobile mass spectrometers for on-site analysis and monitoring have been constructed. The mass analyzer is usually ion trap, quadrupole or time-of-flight. Detection limits were found to be in the sub-picogram range $[14,15]$.

Tandem mass spectrometry (MS/MS) [1,2] (Fig. 1) has been used in MS explosives detectors in order to increase selectivity [4]. In MS/ MS, after mass analysis of the ionized sample, a preselected precursor ion will collide with an inert gas, such as helium or nitrogen, resulting in collision-induced dissociation (CID). The fragment ions thus produced are mass analyzed and recorded. The MS/MS-CID mass spectrum provides a "fingerprint" of the precursor ion and provides an additional dimension of selectivity in the identification of the analyzed sample.

A real-time sampling and MS detection system was developed [17]. In this system particles are removed from the surface to be examined, transported along a flexible tube, and deposited on a moving belt. The explosives are then thermally desorbed and the vapor is transferred into the ionization region for subsequent ionization and mass analysis by MS/MS.

\subsection{Bulk detection}

Bulk-detection methods use penetrating radiation that interacts with certain nuclei characteristic to explosives. Although many of these instruments are quite large, they have been placed in airports to detect hidden explosives in luggage.

\subsubsection{X-rays}

$\mathrm{X}$-rays useful for detection of explosives have energies from a few thousand up to several million electron volts. Various X-ray detection systems [2] have been used, based on dualenergy analysis, low-angle X-ray scattering or computed tomography (CT). A commercial

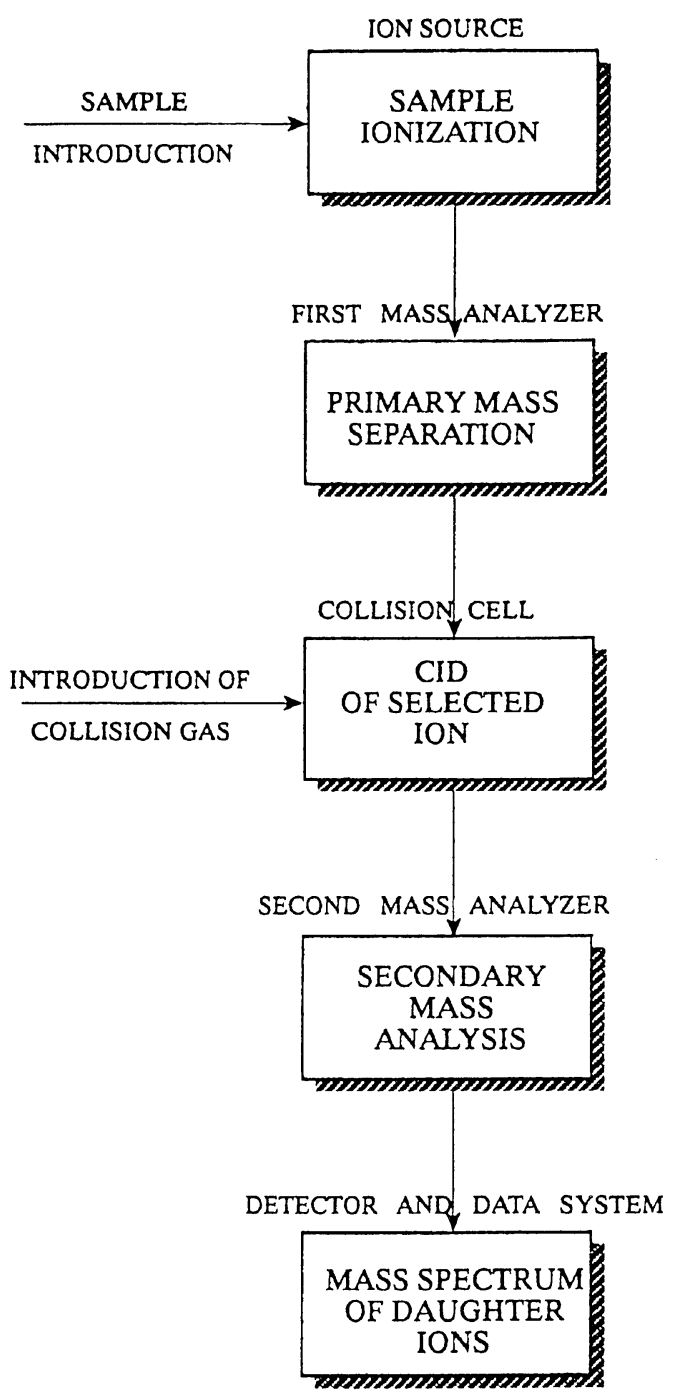

Fig. 1. Schematic diagram of an MS/MS system. 
detection system for airport baggage, based on CT technology, was found to have a throughput rate of up to 800 bags per hour [18]. No quantitative data on sensitivity and false alarm rate have been published.

\subsubsection{Neutron analysis}

Thermal neutron analysis (TNA), fast neutron analysis (FNA) and pulsed fast/thermal neutron analysis (PFTNA) are based on the excitation of elements in the explosives by neutrons. TNA [19] uses the capture of low-energy neutrons in the nitrogen of the explosive and measures the resulting characteristic capture gamma ray. Fig. 2 shows the nitrogen density of common materials and explosives. FNA [20] uses pulses of higher energy neutrons that create characteristic gamma rays from nitrogen and other constituents, such as oxygen, carbon or chlorine, found in the high-explosive charge. PFTNA [21] uses pulses of high-energy neutrons to initiate several types of nuclear reactions in the scrutinized object. The gamma rays from these reactions on elements such as $\mathrm{C}$ and $\mathrm{O}$ are detected and stored. Some of the fast neutrons, after thermalization, are captured by elements, such as $\mathrm{H}$ and $\mathrm{N}$, to produce gamma rays. The scrutinized object is characterized by the gamma rays originating from the fast and thermal neutron reactions.

\subsubsection{Nuclear quadrupole resonance (NQR)}

NQR is tuned to respond to the interaction of radio-frequency (RF) energy with nitrogen in

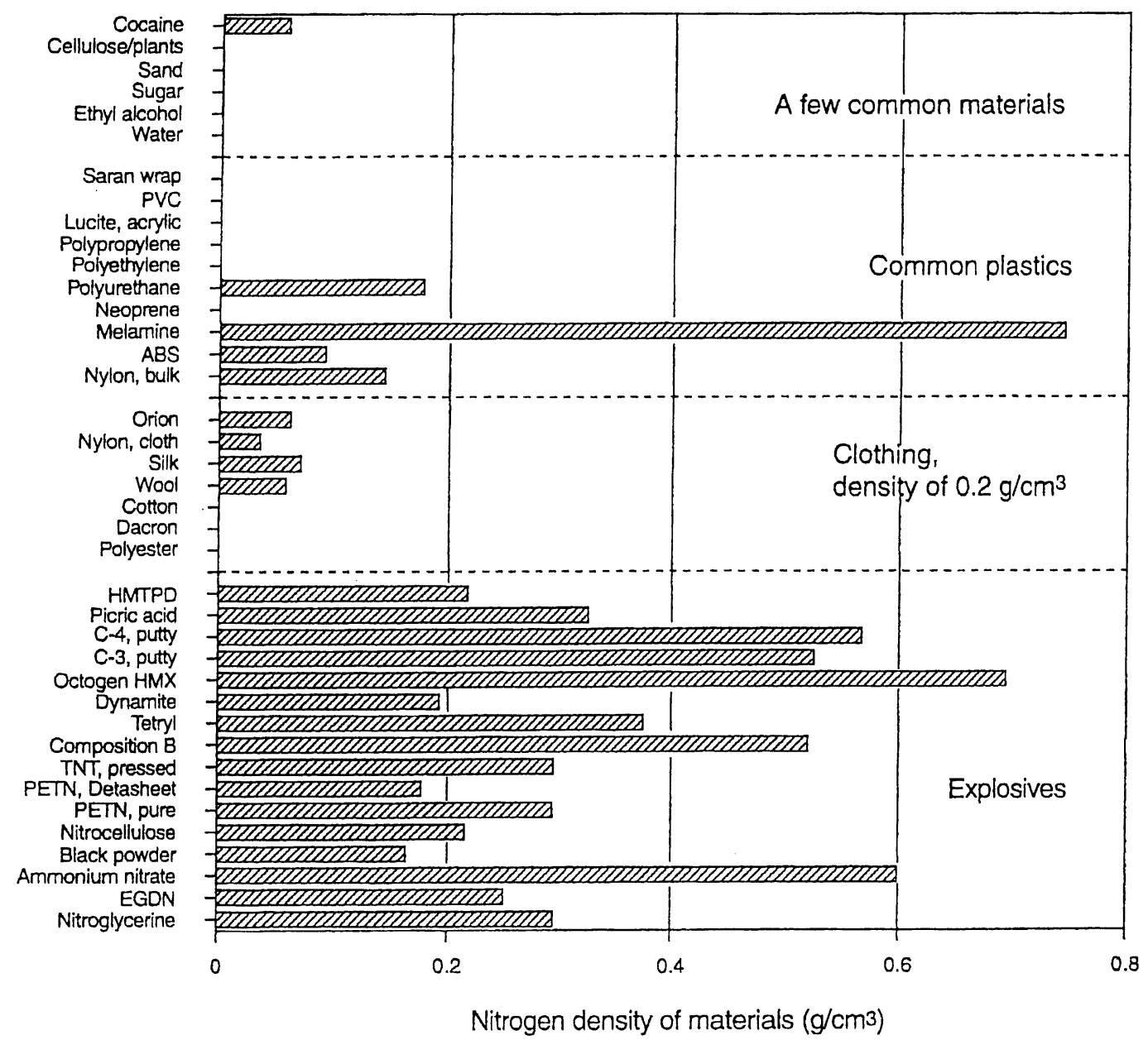

Fig. 2. Nitrogen density of common materials and explosives. Reproduced from Reports OTA-ISC-481 (1991) and OTA-ISC-511 (1992), US Congress, Office of Technology Assessment, Washington, DC, USA. 
the crystalline structure of explosives, such as RDX, which is a major explosive in many plastic formulations [22,23]. According to the manufacturer of a commercial NQR detection system, it has a false alarm rate of less than $3 \%$ [18].

\subsection{Explosives-detection portals [2,24]}

The portal is intended to identify passengers who have recently handled explosives. The portals look like an airport metal detector with vents and nozzles on its inside walls and ceiling. The passenger stands inside the portal for a few seconds or passes through, while a gentle flow of air is passed over him. The air sample is then collected, concentrated and passed through a detector that recognizes any explosive present. The detector can be ECD, TEA, IMS or MS. Current portals with trace detection based on IMS, ECD and TEA have sensitivities in the parts per trillion (ppt) range [24]. The analysis time of such a portal with IMS detection is about seven people per minute [25]. An MS/ MS-based personnel-screening portal was developed using a combination of ion trap and time-of-flight mass analyzers [26]. Explosive vapor-detection limits were in the ppt range and residue-detection limits in the low-picogram range. Detector response time was $2 \mathrm{~s}$.

\subsection{Scanning documents}

People routinely handle their identification cards, boarding passes or other documents, thus transferring any explosives residue from their fingertips onto their documents.

A document scanner can collect any trace particles that might have been deposited through routine handling and identify them. The detectors that have been used for scanning documents are IMS and MS. An automated system was built with an MS/MS triple-quadrupole mass spectrometer detector [27]. The desorption of explosives from the passes was carried out with short-wave infrared radiation. The vapors produced were drawn into the MS/ MS mass spectrometer and monitored. Detection limits, from the surface of boarding passes, were less than $100 \mathrm{pg}$ for TNT, RDX, PETN and NG. The system was able to handle a throughput rate of 1000 boarding passes per hour. The desorption (from the boarding cards) efficiency of the system was found to be between $70 \%$ and $100 \%$, depending on the thickness of the card used.

\section{Environmental detection and monitoring of explosives}

It has been known for many years that most explosives are toxic [28]. Therefore, they not only present a health hazard to munition workers and military personnel who handle them, but also constitute a general environmental problem. The disposal of obsolete explosives and munitions was not always carried out in an environmentally acceptable manner. Explosives and ammunition used to be buried in the ground and explosives-containing wastewater from explosives and munition manufacture used to be discharged into rivers and streams.

In order to assess the extent of explosive contamination in suspected areas, it is necessary to detect and identify the explosives and their degradation products in groundwater and soil. It is important to be able to detect the explosives on-site in the contaminated area, using field tests or mobile detectors. Fast screening is essential for the determination of explosives in soil before they decompose and leach into the groundwater.

Some of the analytical methods, such as GC, high-performance liquid chromatography (HPLC), GC/MS and IMS, have been adapted for use in field analyses of explosives. However, some explosive detectors have been specially developed for environmental detection and/or screening of explosives on site.

\subsection{Immunochemical detection methods}

Immunoassays are immunochemical detection methods based on a reaction between a target analyte and a specific antibody [29]. Quantitation is achieved by monitoring a color change or by measuring radioactivity or fluorescence. 


\subsubsection{Enzyme-linked immunosorbent assays}

In the enzyme-linked immunosorbent assay (ELISA), the specificity of the antibody for the analyte and the resultant immune complex is the basis of these immunoassays.

An ELISA has been developed for TNT and other nitrocompounds [30]. TNT could be detected within the range $0.02-20 \mu \mathrm{g} / \mathrm{L}$, with a detection limit of about $20 \mathrm{ng} / \mathrm{L}$. This method was used in a portable device for rapid field screening for TNT in water and soil [31]. A quantitative color response was obtained to concentrations of TNT in the range $1-30 \mu \mathrm{g} / \mathrm{L}$ in water and $50-1000 \mu \mathrm{g} / \mathrm{kg}$ in soil.

\subsubsection{Fiber-optic biosensor}

The fiber-optic biosensor is based on a competitive fluoroimmunoassay performed on the surface of an optical fiber probe [32-34].

When antibodies, immobilized on the fiber surface, bind the fluorescently labeled TNT analog (or RDX analog), laser light in the evanescent wave excites the fluorophore, generating a signal. TNT (or RDX), present in the sample, prevents such binding, thereby decreasing the signal. Detection limits of TNT and RDX in groundwater were $5 \mu \mathrm{g} / \mathrm{L}$ [33]. Detection limits of TNT and RDX in soil acetone extracts were $0.5 \mathrm{mg} / \mathrm{kg}(0.1 \mathrm{mg} / \mathrm{L})$ [34].

\subsubsection{Displacement flow immunosensor}

The biosensor uses antibody recognition of analyte molecules and subsequent fluorescence detection downstream to measure TNT and RDX levels in groundwater and soil [35-37]. The system comprises either fused-silica capillaries or activated porous membranes (onto which either TNT or RDX antibodies are immobilized and saturated with labeled antigen), which are inserted into microreactor columns that are incorporated in a flow system.

Target analyte is introduced upstream of the microreactor, while the displacement of labeled antigen is monitored downstream by a fluorometer. The concentration of displaced labeled antigen detected is proportional to the concentration of the target analyte introduced into the system.

Fig. 3 is a schematic diagram of a dual analyte capillary-based displacement flow immunosensor system [35]. This system comprises two capillaries, one coated with antibodies specific for TNT and the other specific for RDX.

The detection limit for the membrane-based format [37] was $1 \mathrm{ng} / \mathrm{ml}$, which corresponded to a detection limit of about $80 \mathrm{ppt}$ for TNT and RDX. The sensor was reusable and suitable for continuous monitoring of explosives, with an operating lifetime of over 50 positive samples.

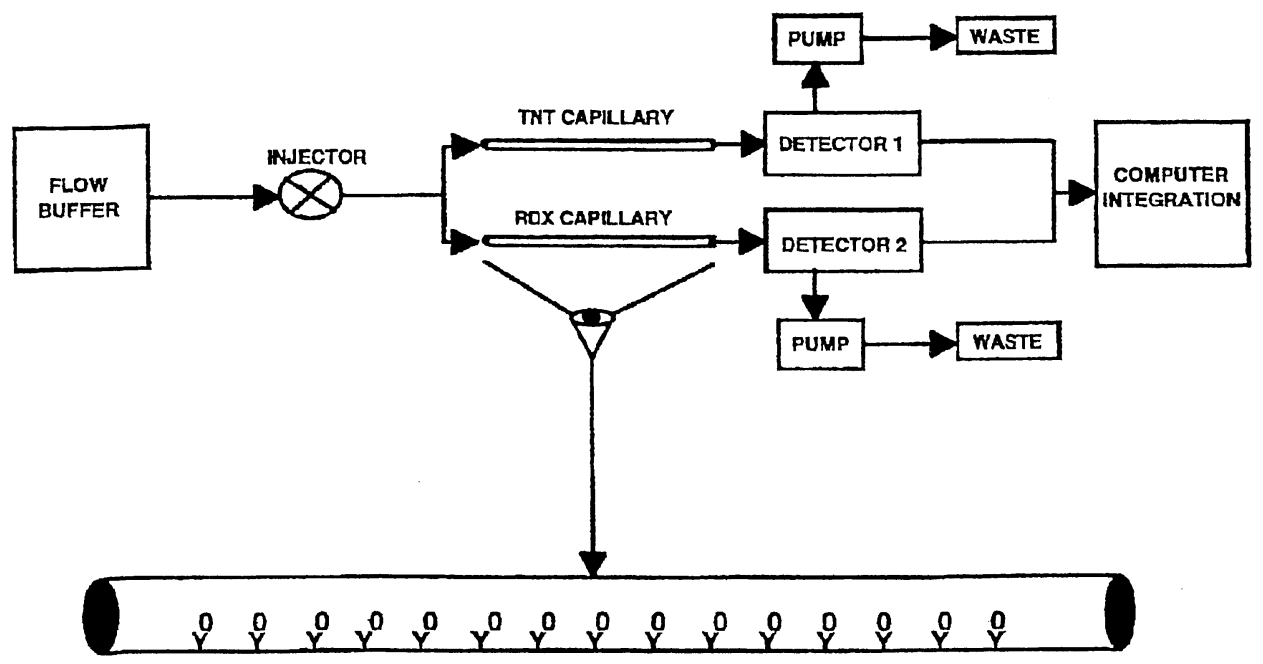

Fig. 3. Schematic diagram showing the dual-analyte, capillary-based, displacement-flow immunosensor system. $Y^{\circ}$ represents the antibodies immobilized to the walls of the capillary and saturated with bound labeled antigen. Reproduced with permission from [35]. ( C) Copyright 1998 by Academic Press). 


\subsection{Electrochemical detection methods}

\subsubsection{Amperometric gas sensor}

In amperometric gas sensors, measurements are made by recording the current in the electrochemical cell between working (or sensing) and counter (or auxiliary) electrodes at a certain potential. As gas sensors are not sensitive enough to measure directly TNT vapor, a system was developed in which characteristic catalytic degradation products of TNT, undergoing pyrolysis, were detected [38].

The method, for in-situ detection of TNT in contaminated soils, was based on thermal decomposition of TNT over platinum and measurement of the nitric oxide (NO) vapor generated by miniature amperometric sensors. A penetrometer system probe was designed to accommodate the electrochemical sensor for measurement of explosive contamination [39]. An amperometric sensor with gold electrodes was used to detect selectively nitrogen oxides; it does not detect $\mathrm{CO}$ and $\mathrm{CO}_{2}$. The sensor response was reproducible with a precision of $\pm 10 \%$. The sensor response was proportional to soil concentration of TNT over the range of $1-500 \mathrm{ppm}$, with an analysis time of less than $4 \mathrm{~min}$.

\subsubsection{Voltammetry sensors}

Potentiometric sensors based on cyclic voltammetry [40] and square-wave voltammetry [41] were developed for the detection of TNT in water and soil. Cyclic voltammograms and square-wave voltammograms, respectively, were recorded to determine the potentials corresponding to the peak currents, which were found to be directly proportional to the TNT concentration. Detection limits were about 200 $\mu \mathrm{g} / \mathrm{L}$ and $30 \mu \mathrm{g} / \mathrm{L}$ for river and drinking water samples, respectively, with a signal-to-noise ratio of 3 [41].

\section{Detection of landmines}

There are at least 125 million unexploded landmines buried in 70 countries around the world. The concept of the landmine is very simple: a sensor detects a target, which activates a sensitive detonator, which in turn sets off a larger quantity of a high explosive.

All the components are encased in metal, plastic, ceramic or wood. The most used explosive for the main charge is TNT. Other explosives used are RDX, Composition B (RDX + TNT), tetryl and C-4 (RDX-based). In addition, mines have a booster charge to enhance the power released by the detonator. Landmines can be classified into two groups: (1) antitank mines, designed to be triggered by heavy vehicles, containing 2-10 kg of explosive and activated by pressures of hundreds of $\mathrm{kg}$; and, (2) antipersonnel mines, containing 10-250 g of explosive, designed to detonate under pressures of $0.5-50 \mathrm{~kg}$.

The inherent difficulty of mine clearance is complicated by the great variety of mines in use. More than 700 types are known, they come in a variety of sizes and shapes, they are made of many different materials, and they are found in various locations and soil matrix conditions. Most modern landmines contain only a small amount of metal, so that traditional detection techniques based on metal detectors are less useful than before. Table 2 gives a list of some common antipersonnel landmines, including the type of explosive(s) used in each [2].

Detection methods can be subdivided into anomaly detectors and detectors based on chemical sensing of explosives.

\subsection{Anomaly detectors [2]}

Anomaly detectors detect objects that are not expected in their natural environments. They include: manual mine clearance by prodding the ground; metal detectors; magnetometers; mechanical detection techniques; ground penetrating radar (GPR); infrared imaging; and, backscattered X-rays.

\subsection{Chemical sensors}

Distinct from anomaly detectors, which look for the container holding the explosive, chemical 
Table 2

List of common anti-personnel landmines [2]

\begin{tabular}{|c|c|c|c|c|c|c|c|}
\hline Type & Manufacturing country & $\begin{array}{l}\text { Weight } \\
{[\mathrm{kg}]}\end{array}$ & $\begin{array}{l}\text { Mine-case } \\
\text { material }\end{array}$ & $\begin{array}{l}\text { Mine-case } \\
\text { color }\end{array}$ & Mine fuse & $\begin{array}{l}\text { Explosive } \\
\text { charge }\end{array}$ & $\begin{array}{l}\text { Explosive } \\
\text { weight }[\mathrm{g}]\end{array}$ \\
\hline Type 69 & China & 1.35 & Cast iron & Olive drab & Pressure or tripwire & TNT & 105 \\
\hline Type 72 & China, S. Africa & 0.125 & Plastic & Green & Pressure & $\begin{array}{l}\text { TNT/RDX } \\
(50 / 50)\end{array}$ & 75 or 100 \\
\hline M14 & USA, India & 0.158 & Plastic & Olive drab & Pressure & Tetryl & 29 \\
\hline M16A1 & USA & 3.57 & Steel & Green & Trip wire, pressure & TNT & 513 \\
\hline M18A1 & USA, Chile, South Korea & 1.58 & Plastic & Olive drab & Command detonation & $C-4$ & 682 \\
\hline Valmara 69 & Italy & 3.3 & Plastic & Green, sand & Trip wire, pressure & Comp. B & 597 \\
\hline VS-50 & Egypt, Italy, Singapore & 0.185 & Plastic & $\begin{array}{l}\text { Olive drab, } \\
\text { sand }\end{array}$ & Pressure & RDX & 43 \\
\hline PP-MI-SR & Czech Republic & 3.2 & $\begin{array}{l}\text { Steel, } \\
\text { plastic }\end{array}$ & Olive drab & Trip wire, pressure & TNT & 362 \\
\hline MON-200 & Russia & 25 & Metal & Olive drab & $\begin{array}{l}\text { Trip wire, } \\
\text { command detonation }\end{array}$ & TNT & $12 \mathrm{~kg}$ \\
\hline $\mathrm{PMN}$ & Russia, Iraq & 0.55 & Bakelite & Black & Delay-armed, pressure & TNT/Tetryl & 200 \\
\hline POMZ-2 & $\begin{array}{l}\text { Russia, North Korea, } \\
\text { Germany, China }\end{array}$ & 2.3 & Metal & Olive drab & Trip wire & TNT & 75 \\
\hline PMD-6 & Russia & 0.4 & Wood & Natural wood & Pressure & TNT & 200 \\
\hline
\end{tabular}

sensors look for the explosive contained inside the landmine, either by sniffing the explosive vapor or by bulk detection.

\subsubsection{Vapor detection}

When a landmine is buried in the ground, vapors emanating from the explosive begin to leak from the landmine into the soil. A fraction of these explosive vapors reach the surface of the ground and can be detected [42]. Two types of methods have been suggested:

a. Explosive vapor detectors similar to those used to detect hidden explosives in airport luggage and mail (see paragraph 2.1. above)

b. Artificial sensors. Efforts are being made to produce an "electronic nose", using advanced material technology [43-46].

A sensor, using novel fluorescent polymers, has been developed to detect TNT and other landmine-signature vapors in air [47]. Thin film of these polymers undergoes a large reduction in emission intensity when molecules of TNT bind to the polymer, resulting in an amplification of the fluorescence-quenching response. The polymer structure contains receptor sites designed to interact specifically with nitroaro- matic explosives, thus enhancing the selectivity of the polymers for the analytes emanating from the landmines. Detection limit of TNT in headspace samples was found to be $1 \mathrm{fg}$ at a signal-to-noise ratio of 3 .

\subsubsection{Bulk detection}

a. Neutron analysis (see paragraph 2.2.2) [48].

b. Nuclear quadrupole resonance (NQR) (see paragraph 2.2.3) [49].

\section{Summary}

Mobile and hand-held explosives detectors have been developed for field detection of explosives in various applications, such as airport luggage, environmental monitoring and detection of landmines.

The principles of operation of the main detectors in use are based on: ionization and separation analysis of the explosive vapor; pyrolysis and gas-phase reactions; bulk detection by means of a reaction of an incident radiation with an element or elements of the explosive compound; and, detection of a product of a biochemical reaction with the explosive. 


\section{References}

[1] J. Yinon, S. Zitrin, Modern Methods and Applications in Analysis of Explosives, John Wiley \& Sons, Chichester, 1993.

[2] J. Yinon, Forensic and Environmental Detection of Explosives, John Wiley \& Sons, Chichester, 1999.

[3] S. Nacson, L. McNelles, S. Nargolwalla, D. Greenberg, Proc. 2nd Explosives Detection Technology Symposium \& Aviation Security Technology Conference, Atlantic City, NJ, USA, 1996. p. 38.

[4] A.L. Lafleur, K.M. Mills, Anal. Chem. 53 (1981) 1202.

[5] E.U. Goff, W.C. Yu, D.H. Fine, Proc. 1st Int. Symposium on Analysis and Detection of Explosives, Quantico, VA, USA, 1983, p. 159.

[6] D.P. Rounbehler, S.J. MacDonald, D.P. Lieb, D. H. Fine, Proc. 1st Int. Symposium on Explosives Detection Technology, Atlantic City, NJ, USA, 1991, p. 703.

[7] Anon, http://www.thermodetection.com/egis_01.cfm: Thermodetection, Inc., Chelmsford, MA 01824, USA (2001).

[8] R.H. St Louis, H.H. Hill Jr., Crit. Rev. Anal. Chem. 21 (1990) 321.

[9] R.G. Ewing, D.A. Atkinson, G.A. Eiceman, G.J. Ewing, Talanta 54 (2001) 515.

[10] D.D. Fetterolf, T.D. Clark, J. Forensic Sci. 38 (1993) 28.

[11] Anon, http://www.barringer.com/html/product_info. html: Barringer Technologies, Inc., Warren, NJ 07059, USA (2001).

[12] F. Kuja, A. Grigoriev, A. Loveless, R. Jackson, R. James, S. Nacson, Proc. 7th Int. Symposium on Analysis and Detection of Explosives, Edinburgh, Scotland, 2001, p. 127.

[13] W.R. Davidson, B.A. Thomas, A.K. Akery, R. Sleeman, Proc. 1st Int. Symposium on Explosives Detection Technology, Atlantic City, NJ, USA, 1991, p.653.

[14] H.G. Lee, E.D. Lee, M.L. Lee, Proc. 1st Int. Symposium on Explosives Detection Technology, Atlantic City, NJ, USA, 1991, p.619.

[15] S.A. McLuckey, D.E. Goeringer, K.G. Asano, G. Vaidyanathan, J.L. Stephenson Jr., Rapid Commun. Mass Spectrom. 10 (1996) 287.

[16] J.A. Syage, M.A. Hanning-Lee, K.A. Hanold, Field Anal. Chem. Technol. 4 (2000) 204.

[17] R. Sleeman, G. Bennett, W.R. Davidson, W. Fisher, Proc. Int. Symposium on Contraband and Cargo Inspection Technologies, Washington, DC, USA, 1992, p.57.

[18] Anon, http://www.invision-tech.com/products: InVision Technologies, Inc., Newark, CA 94560, USA (2001).

[19] P. Shea, T. Gozani, H. Bozorgmanesh, Nucl. Instr. Meth. Phys. Res. A 299 (1990) 444.

[20] C.L. Fink, B.J. Miklich, T.J. Yule, P. Humm, L. Sagalovsky, M.M. Martin, Nucl. Instr. Meth. Phys. Res. B 99 (1995) 748.

[21] G. Vourvopoulos, P.C. Womble, Talanta 54 (2001) 459.

[22] M.L. Buess, A.N. Garroway, J.B. Miller, J.P. Yesinowski, Explosives detection by ${ }^{14} \mathrm{~N}$ pure NQR. In: J. Yinon (Editor), Advances in Analysis and Detection of Explosives, Kluwer Academic Publishers, Dordrecht, The Netherlands, 1993, p.361.

[23] M. Ostafin, B. Nogaj, Appl. Magn. Reson. 19 (2000) 571.

[24] S.F. Hallowell, Talanta 54 (2001) 447.
[25] Anon, http://www.barringer.com/html/sentinel.html: Barringer Technologies, Inc., Warren, NJ 07059, USA (2000).

[26] K.A. Hanold, Proc. 7th Int. Symposium on Analysis and Detection of Explosives, Edinburgh, Scotland, 2001, p. 13.

[27] S.L. Richards, R. Sleeman, I.F.A. Burton, J.G. Luke, G.T. Carter, W.R. Stott, W.R. Davidson, Proc. 7th Int. Symposium on Analysis and Detection of Explosives, Edinburgh, Scotland, 2001, p. 60.

[28] J. Yinon, Toxicity and Metabolism of Explosives, CRC Press, Boca Raton, 1990.

[29] J.M. Van Emon, V. Lopez-Avila, Anal. Chem. 64 (1992) 78A.

[30] C. Keuchel, L. Weil, R. Niessner, Anal. Sci. 8 (1992) 9.

[31] C. Keuchel, R. Niessner, Fres. J. Anal. Chem. 350 (1994) 538.

[32] L.C. Shriver-Lake, K.A. Breslin, P.T. Charles, D.W. Conrad, J.P. Golden, F.S. Ligler, Anal. Chem. 67 (1995) 2431.

[33] S.K. van Bergen, I.B. Bakaltcheva, J.S. Lundgren, L.C. Shriver-Lake, Environ. Sci. Technol. 34 (2000) 704.

[34] L.C. Shriver-Lake, C.H. Patterson, S.K. van Bergen, Field Anal. Chem. Technol. 4 (2000) 239.

[35] U. Narang, P.R. Gauger, A.W. Kusterbeck, F.S. Ligler, Anal. Biochem. 255 (1998) 13.

[36] A.W. Kusterbeck, P.T. Charles, Field Anal. Chem. Technol. 2 (1998) 341.

[37] S.Y. Rabbany, W.J. Lane, W.A. Marganski, A.W. Kusterbeck, F.S. Ligler, J. Immunol. Meth. 246 (2000) 69.

[38] W.J. Buttner, M. Findlay, W. Vickers, W.M. Davis, E.R. Cespedes, S. Cooper, J.W. Adams, Anal. Chim. Acta 341 (1997) 63.

[39] J. Wormhoudt, J.H. Shorter, J.B. McManus, P.L. Kebabian, M.S. Zahniser, W.M. Davis, E.R. Cespedes, C.E. Kolb, Appl. Optics 35 (1996) 3992.

[40] M. Krausa, J. Doll, K. Schorb, W. Boke, G. Hambitzer, Propellants, Explosives, Pyrotechnics 22 (1997) 156.

[41] J. Wang, R.K. Bhada, J. Lu, D. McDonald, Anal. Chim. Acta 361 (1998) 85.

[42] T.F. Jenkins, D.C. Leggett, P.H. Miyares, M.E. Walsh, T.A. Ranney, J.H. Cragin, V. George, Talanta 54 (2001) 501.

[43] B.J. Doleman, R.D. Sanner, E.J. Severin, R.H. Grubbs, N.S. Lewis, Anal. Chem. 70 (1998) 2560.

[44] J. White, J.S. Kauer, T.A. Dickinson, D.R. Walt, Anal. Chem. 68 (1996) 2191.

[45] J.-S. Yang, T.M. Swager, J. Am. Chem. Soc. 120 (1998) 5321.

[46] P. Kobrin, C. Seabury, C. Linnen, A. Harker, R. Chung, R.A. McGill, P. Matthews, Thin film resonators for TNT vapor detection. Conference on Detection and Remediation Technologies for Mines and Mine-like Targets III, Orlando, FL, 1998: SPIE Proceedings, 3392 (1998) 418.

[47] C.J. Cumming, C. Aker, M. Fisher, M. Fox, M.J. la Grone, D. Reust, M.G. Rockley, T.M. Swager, E. Towers, V. Williams, IEEE Trans. Geoscience Remote Sensing 39 (2001) 1119.

[48] E.M.A. Hussein, E.J. Waller, Appl. Rad. Isotopes 53 (2000) 557.

[49] A.N. Garroway, M.L. Buess, J.B. Miller, B.H. Suits, A.D. Hibbs, G.A. Barrall, R. Matthews, L.J. Burnett, IEEE Trans. Geoscience Remote Sensing 39 (2001) 1108. 
Dr. Jehuda Yinon received his B.Sc. and M.Sc. degrees in electrical engineering from the Technion, Israel Institute of Technology, Haifa, Israel, and his Ph.D. in physical chemistry from the Weizmann Institute of Science, Rehovot, Israel.

$\mathrm{He}$ is currently professor of forensic science and assistant director for research in physical and chemical sciences at the National Center for Forensic Science, University of Central Florida, Orlando, Florida, USA.

Dr. Yinon was a senior research fellow at the Weizmann Institute of Science for 35 years. During this time, he spent sabbatical leaves at: Caltech's Jet Propulsion Laboratory (Pasadena, CA, USA); National Institute of Environmental Health Sciences (Research Triangle Park, NC,USA); EPA Environmental Monitoring Systems Laboratory (Las Vegas, NV,USA); Centre National de la Recherche Scientifique (Lyon, France); and, at the University of Florida (Gainesville, FL, USA).

Dr. Yinon's main research interests are applications of novel mass spectrometry techniques in forensic and environmental sciences, with emphasis on analysis and detection of explosives. 